\title{
Functional and radiological outcome of valgus osteotomy (abduction osteotomy of Pauwel) and fixation with dynamic hip screw in neglected fracture neck of femur
}

\author{
Venugopal S. M.*, Naveen Babu, Naresh Odnala, Gudaru Jagadesh
}

Department of Orthopaedics, BIRRD Trust Hospital, Tirupati, Andhra Pradesh, India

Received: 14 July 2020

Revised: 29 July 2020

Accepted: 30 July 2020

\section{*Correspondence:}

Dr. Venugopal S. M.,

E-mail: shring31@gmail.com

Copyright: () the author(s), publisher and licensee Medip Academy. This is an open-access article distributed under the terms of the Creative Commons Attribution Non-Commercial License, which permits unrestricted non-commercial use, distribution, and reproduction in any medium, provided the original work is properly cited.

\begin{abstract}
Background: Despite improvements in the techniques of surgery and internal fixation devices, non-union is still reported in one-third of cases of femoral neck fracture with displacement. Valgus intertrochanteric osteotomy alters the biomechanical environment of the fracture site and restores limb length.

Methods: This was a prospective study on functional outcome of valgus osteotomy and fixation with dynamic hip screw (DHS) in neglected fracture neck of femur in Balaji Institute of Surgery, Research and Rehabilitation for the Disabled (BIRRD), Tirupati. 28 patients were enrolled between December 2017 to December 2019. Patients less than 60 years of age with fracture neck of femur of more than or equal to 3 weeks since injury and with failed primary fixation were included. Patients $>60$ years of age, patients with avascular necrosis (AVN), and with resorption of femoral neck were excluded.

Results: Among 28 patients 12 had union within 6 months and another 12 within 12 months. 4 patients were lost for follow-up hence considered as non-union. Osteotomy site united by 6 months in 22 patients and by 12 months in 2 . Harris hip score was fair to excellent in 24 patients and poor in 4.

Conclusions: Valgus osteotomy and DHS fixation is often a definitive one-time surgical procedure to achieve union in neglected and ununited fracture neck femur in young patients. It is simple and biological. In this study because of the delay in presentation and the young age of patients, Pauwels' osteotomy was performed as the head-salvaging procedure. Union was achieved in $86 \%$ of this study patients.
\end{abstract}

Keywords: Abduction osteotomy of Pauwel, Dynamic hip screw, Neglected fracture neck of femur

\section{INTRODUCTION}

Fracture neck of femur is one of the commonly encountered injuries in orthopaedics. It remains an unsolved fracture in young, to the orthopaedic surgeon as far as treatment and results are concerned. ${ }^{1}$ The increase in high-energy trauma has contributed to the increased incidence of fracture neck of femur in younger patients. Young and active patients are generally treated by anatomical reduction and internal fixation as soon as possible. In developing countries, late and neglected presentation of femoral neck fractures is common because of many socio-economic reasons like local bone setters, lack of awareness and transport etc. Non-union is a frequent complication following femoral neck fracture. Due to precarious blood supply, difficulty in reduction, strong muscle force, flow of synovial fluid, no cambium layer in periosteum and amount of posterior comminution are the main reasons for non-union and avascular necrosis. To treat the femoral fractures in young adults it is 
important to understand the osseous and vascular anatomy and mechanism of injury, associated injuries, fracture pattern. $^{2}$

Despite improvements in the techniques of surgery and internal fixation devices, non-union is still reported in onethird of cases of femoral neck fracture with displacement. ${ }^{3-}$ 5 Among the head-retaining procedures in such circumstances, various procedures such as fixation with muscle pedicle bone grafting, internal fixation with vascularized or free fibular grafting and valgus osteotomy and internal fixation with angle blade plate and dynamic hip screw are advocated. Valgus intertrochanteric osteotomy alters the biomechanical environment of the fracture site and restores limb length. Few reports have dealt with the results of this procedure internally fixed with dynamic hip screw and double angle barrel plate.

Very little literature is available to show the effectiveness of valgus osteotomy and fixation with dynamic hip screw (DHS) in neglected fractures of femoral neck. Here DHS provides rigid internal fixation of the femoral neck and osteotomy site and also provides a reproducible amount of valgus correction, allowing for preoperative planning and templating of the osteotomy.

\section{METHODS}

This was a prospective study on functional and radiological outcome of valgus osteotomy and fixation with dynamic hip screw in neglected fracture neck of femur in our hospital, Balaji Institute of Surgery, Research and Rehabilitation for the Disabled (BIRRD), Tirupati between December 2017 to December 2019.

There were 28 patients underwent valgus osteotomy and fixed with DHS. All the patients are evaluated as per the proforma prepared. annexure1.

\section{Inclusion criteria}

Inclusion criteria were patients less than 60 years of age with fracture neck of femur of more than or equal to 3 weeks since injury. Patients less than 60 years of age with failed primary fixation.

\section{Exclusion criteria}

Exclusion criteria of this study were elderly patients $(>60$ years of age), patients who had changes of avascular necrosis (AVN) on plain radiography, significant resorption of femoral neck with proximal fragment less than $2.5 \mathrm{~cm}$ were excluded from the study.

\section{Management}

\section{Preoperative assessment}

All the patients are first seen in the outpatient department. Then history regarding the co-morbidities, and assessment of general condition to decide whether patient can tolerate the surgical trauma. Proper counselling was given to patient regarding the surgery, its complications and the post-operative functional abilities and limitations of activity.

After admission, documentation of detailed history and clinical assessment done. Each patient was evaluated with routine blood investigations along with virology. Multidisciplinary approach for surgical fitness is sought by physician, cardiologist, diabetologist, nephrologist etc. Pre-anesthetic check-up is completed. An attempt is made to locate any focus of infection anywhere in the body and treated accordingly. Anti-coagulants, anti-platelet aggregator drugs were stopped before surgery. Informed consent was taken from patient and relatives for surgery pre-operatively.

An anteroposterior radiograph of pelvis with 20 degrees' internal rotation at hips was taken for documentation of fracture and comparison with other hip and to calculate the Pauwels angle. ${ }^{7}$ Lateral view of the involved hip was taken to asses' angulation, displacement of fragments and to note the presence of posterior comminution. Pre-operative Harris hip score was recorded. ${ }^{8}$

\section{Surgical technique}

Under spinal anesthesia with epidural catheter, patient was put on a fracture table and with image intensifier control, with Watson- Jones approach capsulotomy of hip was done and all previous internal fixation devices were removed if any. Precise reduction of the femoral neck fracture was done and the head and neck angle were corrected. $^{9}$

\section{Osteotomy design, barrel plate insertion, osteotomy cuts, osteotomy reduction ${ }^{10-12}$}

Richard's screw and derotation screws were introduced (Figure 1). Side plate was advanced onto the lateral aspect of the femur (Figure 2).

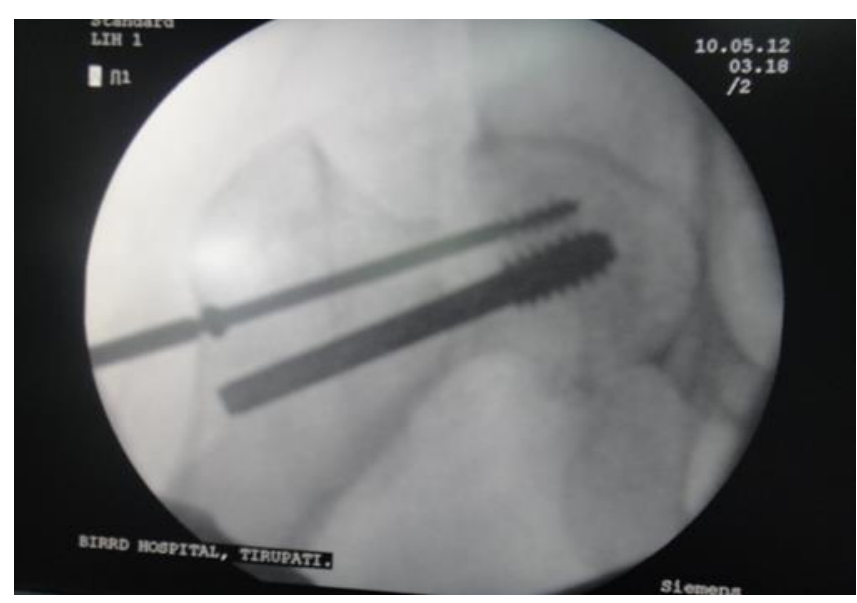

Figure 1: Richard and derotation screw in position. 


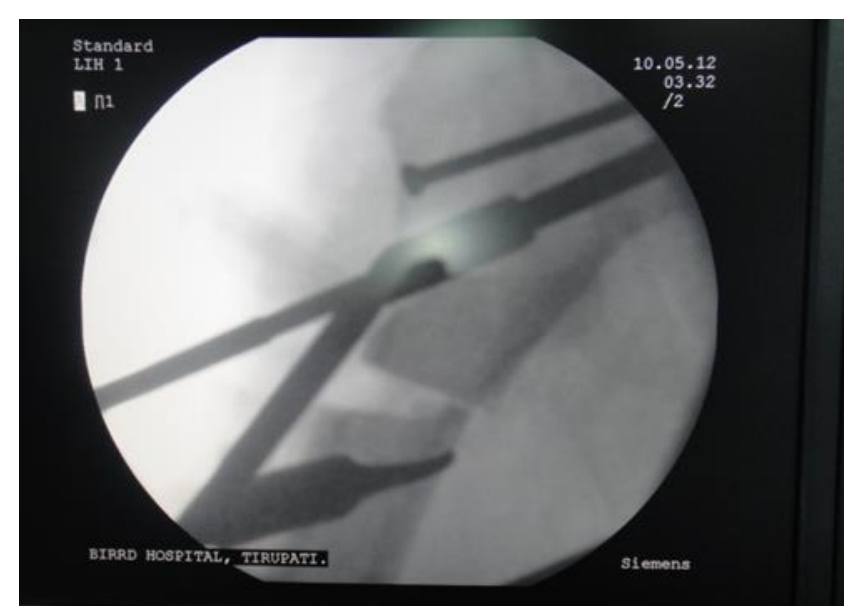

Figure 2: Placement of Barrel and Pauwels osteotomy.

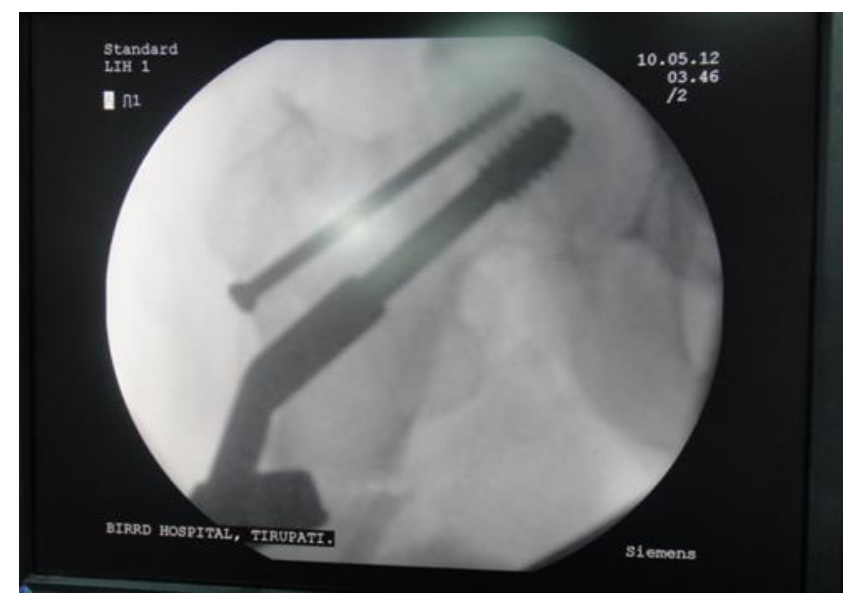

Figure 3: Reduction of barrel and closure of osteotomy.

The level of osteotomy was identified (at the level of the lesser trochanter to allow good bone healing). At the level of osteotomy proximal transverse cut and distal angle cut were made and predetermined size wedge (usually 30 degrees) was removed, lower limb was swung in to abduction to align the femur to plate and reduction clamp were applied (Figure 3). The barrel plate was fixed to femur using $4.5 \mathrm{~mm}$ cortical screw. The removed bone wedge was used as bone graft at osteotomy site. Suction drain was kept above iliotibial band after closure. Wound was closed in layers.

\section{Post-operative management}

Patient was mobilized with touchdown weight bearing for the first six weeks after surgery and then increased to full weight bearing. Active quadriceps, hip strengthening exercises were advised.

\section{Follow-up}

After hospital discharge, patients were observed periodically every six weeks until fracture healing, with periodical radiographs.

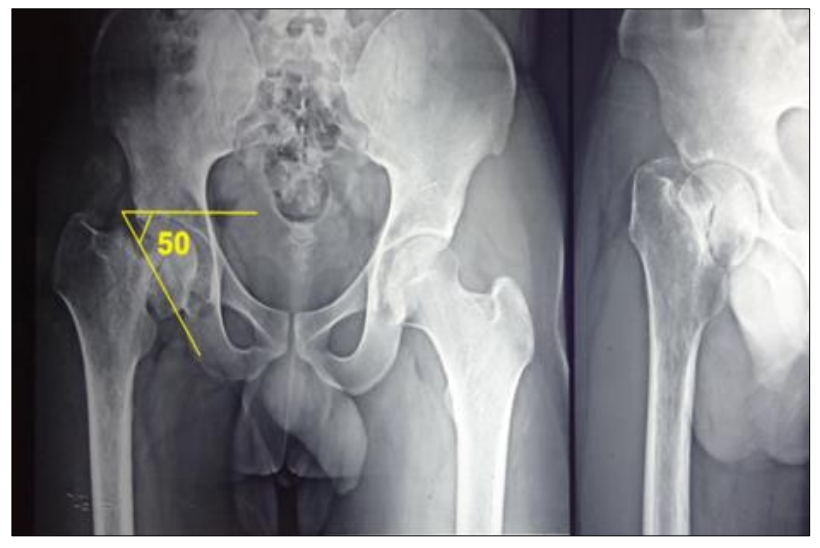

Figure 4: Pre-operative.

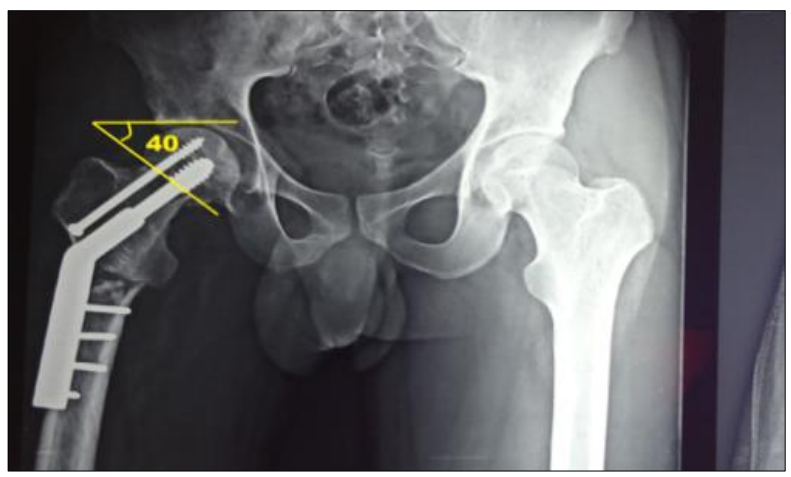

Figure 5: Post-operative follow-up.

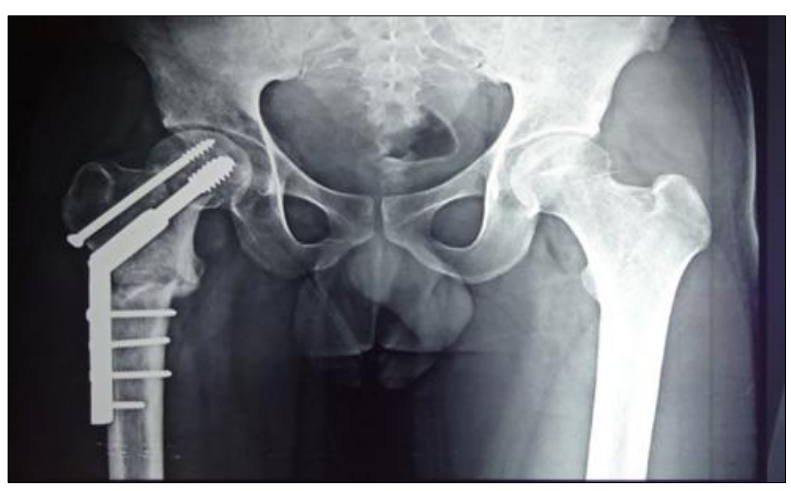

Figure 6: Post 6-week follow-up.

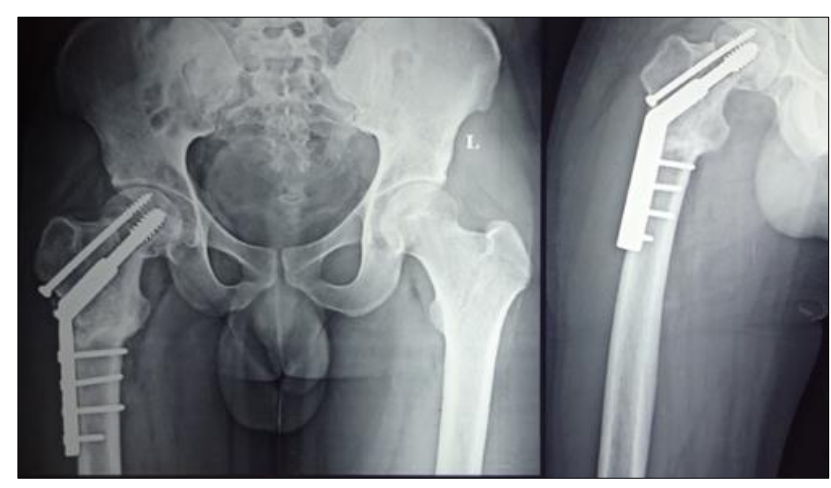

Figure 7: Post 3-month follow-up. 


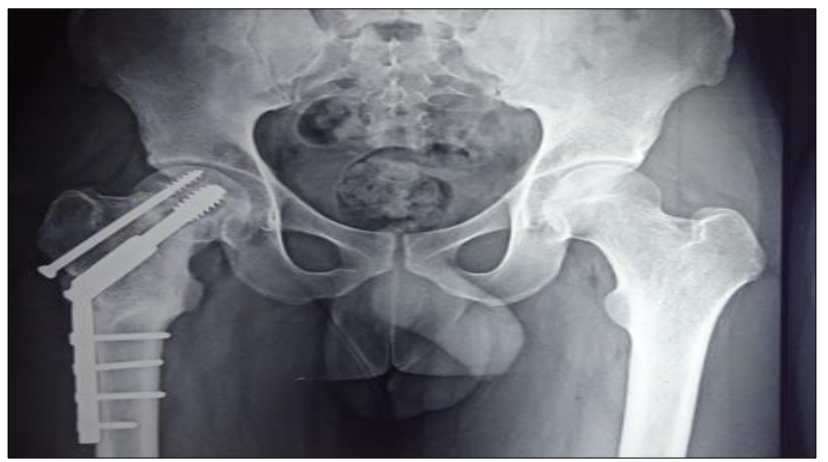

Figure 8: Post 6-month follow-up.

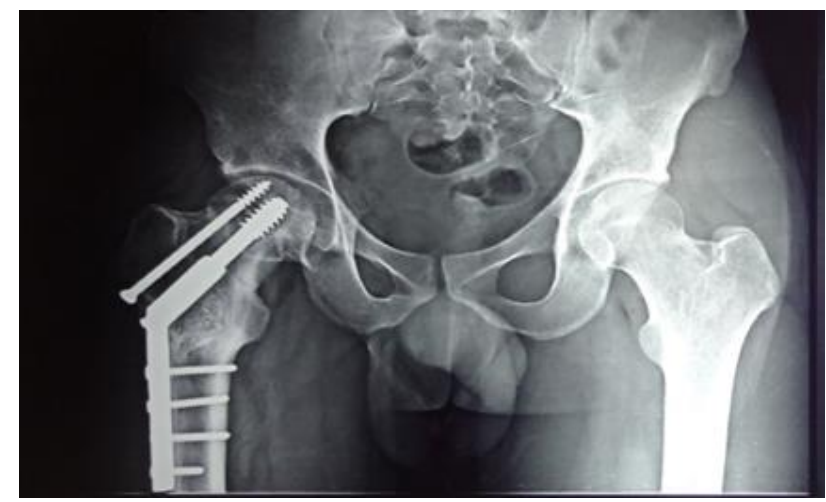

Figure 9: Post 1-year follow-up.

\section{RESULTS}

This study included total of 28 patients from age group 13 years to 48 years averaging about 30 years. Among them 26 were males and remaining 2 were females. Right side was involved in 10 patients and left side in 18 patients. Among 28 patients mechanism of injury was road traffic accident in 16 patients, fall from height in 10 patients, accidental fall in 2 patients. The type of fracture was Pauwels type I in 2 patients, type II in 14 patients, type III in 12 patients. All the data and radiographs were collected from the patients during follow-up at regular intervals. (Table 1 and 2).

Table 1: Age distribution.

\begin{tabular}{|l|l|}
\hline Age in years & No. of patients \\
\hline $\mathbf{1 0}-\mathbf{2 0}$ & 6 \\
\hline $\mathbf{2 1 - 3 0}$ & 8 \\
\hline $\mathbf{3 1 - 4 0}$ & 10 \\
\hline $\mathbf{4 1 - 5 0}$ & 4 \\
\hline Total & 28 \\
\hline
\end{tabular}

Table 2: Mechanism of injury.

\begin{tabular}{|ll|}
\hline Mechanism of injury & No. of patients \\
\hline Road traffic accidents & 16 \\
\hline Fall from height & 10 \\
\hline Accidental fall & 2 \\
\hline
\end{tabular}

Among 28 patients duration from injury to surgery was 36 months in 12 patients, 6-12 months in 12 patients. Average follow up was 12 months ranging from 3 to 21 months. Average age at the time of surgery was 30 years with range from 13 years to 48 years.

Table 3: Harris hip score.

\begin{tabular}{|l|l|}
\hline Harris hip score & No. of patients \\
\hline 90-100- excellent & 6 \\
\hline 80-90- good & 9 \\
\hline 70-79- fair & 9 \\
\hline 60-69- poor & 4 \\
\hline$<60$ - failed & 0 \\
\hline
\end{tabular}

Table 4: Pauwels angle.

\begin{tabular}{|lll|}
\hline Pauwels angle & Pre-operative & Post-operative \\
\hline $\mathbf{3 0 - 5 0}$ & 2 & 16 \\
\hline $\mathbf{5 0 - 7 0}$ & 14 & 6 \\
\hline$>\mathbf{7 0}$ & 12 & 2 \\
\hline
\end{tabular}

Preoperative median Harris hip score was 72 points (range 46 to 87). At 1-year post-op median Harris hip score was 80 points (range 61 to 93 ). The total Harris hip score was excellent (90-100) in 6 patients, good (80-90) in 9 patients, fair (70-79) in 9 patients, poor (60-69) in 4 patients (Table 3).

Pre-operative Pauwels angle was $30-50^{\circ}$ in 2 patients, 50$70^{\circ}$ in 14 patients, $>70^{\circ}$ in 12 patients. Post operatively Pauwels angle was in between $30-50^{\circ}$ in 16 patients, 50 $70^{\circ}$ in 6 patients, $>70^{\circ}$ in 2 patients (Table 4 ).

Table 5: Union.

\begin{tabular}{|lll|}
\hline $\begin{array}{l}\text { Duration (in } \\
\text { months) }\end{array}$ & Fracture site & Osteotomy site \\
\hline $\mathbf{0 - 3}$ & 0 & 0 \\
\hline $\mathbf{4 - 6}$ & 12 & 22 \\
\hline $\mathbf{7 - 1 2}$ & 12 & 2 \\
\hline
\end{tabular}

Among all the 28 patients osteotomy site united within 46 months in 22 patients, with in 1 year in 2 patients (Table 5) (clinical example Figure 4-9).

\section{DISCUSSION}

In developing countries, it is not uncommon to see patients with femoral neck fractures after a delay of several months because of poverty, lack of facilities, ignorance and faith in traditional healers. Salvage of the femoral head has been advocated for younger patients.

Valgus osteotomy converts a shearing force into compression force and fixation with DHS offers additional compression at fracture site. It also increases blood flow, increasing the chances of union. DHS fixation is a common procedure, in case of intertrochanteric fractures, 
hence offers the feasibility of comfort to the operating surgeon. ${ }^{12-14}$

This study had 28 patients from age group 13 years to 48 years averaging about 30 years. Marti et al had 50 patients in their study with their average age being 53 years 9 (range 19 to 76$).{ }^{14}$ Kalra et al had 20 patients with an average age of the patients was 37 years (range: 17-55 years). ${ }^{4}$ Hartfold treated 8 patients with range from $30-43$ years. ${ }^{16}$ Majority of this study cases were secondary to road traffic accidents (RTA) (60\%). Hartfold et al, had $50 \%$ of their cases due to RTA. ${ }^{16}$

Pauwels type II fractures were more common in this series where as both Marti et al and Hartfold et al had majority of their cases in type III group. ${ }^{14,16}$ Post operatively $70 \%$ were in the Pauwels type I group in this study where as Hartfold et al had all their post op cases in type II group. ${ }^{16}$

Harris hip score improved from 46 to 93 in the current series. The average Harris hip score increased from 24 to 73 in the Hartfold group. ${ }^{16}$

Authors had an average time for fracture union was 6 months (range from 4-12) and average time for osteotomy union was 6 months. Hartfold series had their union by an average of 24 months. Major drawback of this study is a short follow-up of 2 years. As per the literature hip osteoarthritis secondary to AVN will be evident by 5 years follow-up (Table 6).

Table 6: Comparison with other studies.

\begin{tabular}{|c|c|c|c|c|c|c|}
\hline Author & $\begin{array}{l}\text { No. of } \\
\text { patients }\end{array}$ & $\begin{array}{l}\text { Minimum } \\
\text { period of neglect }\end{array}$ & $\begin{array}{l}\text { Implant used } \\
\text { for treatment }\end{array}$ & Union (\%) & $\begin{array}{l}\text { Significant } \\
\text { complication }\end{array}$ & $\begin{array}{l}\text { Functional } \\
\text { outcome }\end{array}$ \\
\hline Marti et al ${ }^{14}$ & 50 & 2-60 months & $\begin{array}{l}\text { Double angle } \\
\text { blade plate }\end{array}$ & 86 & $\begin{array}{l}\text { Technical difficulties } \\
\text { in } 6 \text { cases }\end{array}$ & Good \\
\hline Anglen $^{12}$ & 13 & 4-54 weeks & $\begin{array}{l}\text { Double angle } \\
\text { blade plate }\end{array}$ & 100 & Avascular necrosis & Excellent \\
\hline $\begin{array}{l}\text { Kalra and } \\
\text { Anand }^{4}\end{array}$ & 20 & 1-12 months & $\begin{array}{l}\text { Double angle } \\
\text { blade plate }\end{array}$ & 85 & Avascular necrosis & Good \\
\hline Pruthi et al ${ }^{15}$ & 28 & 3-12 weeks & $\begin{array}{l}\text { Double angle } \\
\text { blade plate }\end{array}$ & 88 & Implant cut through & Good \\
\hline $\begin{array}{l}\text { Hartfold et } \\
\text { al }^{16}\end{array}$ & 8 & 5-14 months & Hip screw & 85 & - & Good \\
\hline Khan et al $^{17}$ & 16 & 3-76 weeks & $\begin{array}{l}\text { Double angle } \\
\text { blade plate }\end{array}$ & 87 & Implant cut through & Good \\
\hline Bansal et $\mathbf{a l}^{10}$ & 30 & 4-30 months & $\begin{array}{l}\text { Double angle } \\
\text { blade plate }\end{array}$ & 94 & Implant cut through & Excelent \\
\hline Current study & 28 & 3-18 months & Hip screw & 86 & Non union & Good \\
\hline
\end{tabular}

\section{CONCLUSION}

Authors conclude that valgus osteotomy and fixation with dynamic hip screw has success rate of $80 \%$ in young patients with neglected and ununited intracapsular fracture neck of femur. As far as the union of fracture is concerned fixation with dynamic hip screw provides an additional advantage of compression at fracture site.

\section{Funding: No funding sources}

Conflict of interest: None declared

Ethical approval: The study was approved by the institutional ethics committee

\section{REFERENCES}

1. Jaiswal A, Pruthi KK, Goyal RK, Pathak V, Habib M, Tanwar YS, et al. Evaluation of osteosynthesis with dual fibular bone grafting for neglected femoral neck fractures. J Clin Orthop Trauma. 2013;4(2):5869.
2. Ly TV, Swiontkowski MF. Management of femoral neck fractures in young adults. Indian J Orthop. 2008;42(1):3-12.

3. Baksi DP. Internal fixation of ununited femoral neck fractures combined with muscle-pedicle bone grafting. J Bone Joint Surg Br. 1986;68:239-45.

4. Kalra M, Anand S. Valgus intertrochanteric osteotomy for neglected femoral neck fractures in young adults. Int Orthop. 2001;25:363-6.

5. Smith-Petersen MN, Cave ET, Vangorder GW. Intracapsular fractures of the neck of the femur. Treatment of internal fixation. Arch Surg. 1931;23:715-59.

6. Roshan A, Ram S. The neglected femoral neck fracture in young adults: review of a challenging problem. Clin Med Res. 2008;6(1):33-9.

7. Pauwels F. The fracture of the femoral neck, a mechanical problem: basics of the healing process. Prognosis and causal therapy (ed. Enke, F.) (Stuttgart, 1935); 1935.

8. Harris WH. Traumatic arthritis of the hip after dislocation and acetabular fractures: treatment by 
mold arthroplasty. An end-result study using a new method of result evaluation. J Bone Joint Surg Am. 1969;51(4):737-55.

9. Hoppenfeld S, DeBoer P, Buckley R. Surgical exposures in orthopaedics: the anatomic approach. Lippincott Williams and Wilkins; 2012.

10. Bansal P, Singhal V, Lal H, Mittal D, Arya RK. A convenient way to do valgus osteotomy for neglected fracture neck of femur. Kathmandu Univ Med J. 2013;11(42):147-51.

11. Norouzi M, Alami-Harandi B, Naderi MN. Treatment of nonunion of femoral neck fracture by valgus osteotomy in 33 cases. Eur J Trauma Emerg Surg. 2009;35(5):475.

12. Anglen JO. Inter-trochanteric osteotomy for failed Internal fixation of femoral neck fracture. Clin Orthop. 1997;341:175-82.

13. Ballmer FT, Ballmer PM, Baumgaertel F, Mast JW, Ganz R. Pauwels osteotomy for nonunion of the femoral neck fracture. Orthop Clin North Am. 1990;21:759-67.

14. Marti RK, Schüller HM, Raaymakers EL. Intertrochanteric osteotomy for non-union of the femoral neck. J Bone Joint Surg Br. 1989;71(5):7827.
15. Pruthi KK, Chandra H, Goyal RK, Singh VP. Repositioning osteotomy with dynamic hip screw with $120^{\circ}$ double angled barrel plate fixation in fracture neck femur. Ind J Orthop. 2004;38:92-5.

16. Hartford JM, Patel A, Powell J. Intertrochanteric osteotomy using a dynamic hip screw for femoral neck nonunion. J Ortho Trauma. 2005;19:329-33.

17. Khan AQ, Khan MS, Sherwani MK, Agarwal R. Role of valgus osteotomy and fixation with dynamic hip screw and 120 degrees double angle barrel plate in the management of neglected and ununited femoral neck fracture in young patients. J Orthop Traumatol. 2009;10(2):71-8.

Cite this article as: Venugopal SM, Babu N,

Odnala N, Jagadesh G. Functional and radiological outcome of valgus osteotomy (abduction osteotomy of Pauwel) and fixation with dynamic hip screw in neglected fracture neck of femur. Int J Res Orthop 2020;6:920-5. 